\title{
Service design for public transportation to address the issue of females' fear of crime
}

\author{
Hyunjin $\mathrm{Kim}^{1}$ (D) \\ Published online: 4 September 2019 \\ (c) The Author(s) 2019
}

\begin{abstract}
In conjunction with their gender, how does the current design of public transport services affect female passengers' feelings of safety and fear when using the service? This study explores the influential service design attributes of the London Underground on fear of crime in female users through abductive reasoning, in which a hypothesis is provisionally selected by constantly moving back and forth between data and existing theories to find the best possible explanation of the researched phenomenon. Consequently, it proposes a conceptual model for understanding female passengers' fear of crime in connection with public transport services and suggests influential factors of public transport service design when considering the social problem. It, therefore, draws a more befitting frame of reference for design and improvement of public transport services to ameliorate fear of crime than those based simply on crime prevention.
\end{abstract}

Keywords Service design - Public transport services · Fear of crime $\cdot$ Gender/sex related vulnerability $\cdot$ Grounded theory study

\section{Introduction}

Fear of crime has been dealt with as a common and widespread social problem that leads to a sense of powerlessness (Ross et al. 2001), avoidance of certain places and restricted activities (May et al. 2010; Jackson and Stafford 2009) for vulnerable groups of people. It also has a significant impact on people's use of public transportation. For instance, according to Transport for London (2018), fear of crime appeared most likely to affect Londoners' use of public transport at night.

The seriousness of fear of crime in public transportation manifests itself when compared to the incidence of crime in the same mode of transportation. In the case of the London Underground, there were 9.9 crimes, ranging from violence and threatening or abusive behavior against other passengers to theft of railway property, for every million passenger journeys made in 2017/18 (1 April 2017-31 March 2018) (TFL 2018). However, according to a survey which randomly interviewed 4005 Londoners by telephone, $46 \%$ and $26 \%$

Hyunjin Kim

dr.hyunjin.kim@gmail.com

1 Brunel University, Uxbridge, UK 
of women are shown to be affected by concerns and fear of crime in terms of frequency of their use of the underground after dark and during the day respectively and, in the case of men, $27 \%$ at night and $12 \%$ during the day (TFL 2015). As these statistics represent, a relatively large number of Londoners, in particular, females appear to feel and to be affected by fear of crime in association with using the underground service. In this regard, reducing fear of crime in females and increasing public confidence in the safety of travelling through designing secure environments has been set as an independent key objective of the Mayor's Transport Strategy, separated from reducing crime and antisocial behavior (Mayor of London 2018).

The negative influence of fear of crime in females using public transport services has been acknowledged, as in the case of London. However, efficient ways of managing the specific negative emotion during service transactions has not been sufficiently researched. Design studies related to crime and safety based on 'Defensive Space' and 'Crime Prevention through Environmental Design' (CPTED), in general, incline more towards crime prevention from the potential wrongdoers' point of view (Crowe 2013; Newman 1972). Accordingly, diminishing fear of crime has been expected as a chain reaction to crime prevention, premised on the anticipation that both crime and fear of crime can be reduced through reducing criminal opportunities (Brantingham and Brantingham 1993). The effectiveness of the design approach towards crime prevention on fear, however, has not been proved as research regarding crime prevention states that it 'might be' effective in reducing fear of crime as well.

In addition, the discrepancy between females' perceived risk and actual risk of being involved in criminal activities in London Underground indicates that the solutions for deterring criminals from acts of crime may not all be the same as the solutions for alleviating females' fear of crime in the underground. In general, a greater number of females than males appear to report fear of crime although males are at a higher risk of victimization (Franklin and Franklin 2009; Whitley and Prince 2005) as exemplified in most cases of robbery where the majority of both offenders and victims are male (Brookman et al. 2010). Thus, the paradox between the high levels of fear of crime and the low reported rates of victimization in females suggests taking different approaches towards fear of crime and crime.

The present study suggests influential design attributes of public transportation on females' fear of crime by developing a conceptual model for understanding fear of crime in female passengers. Consequently, it proposes a more befitting design guideline to ameliorate female passengers' fear of crime than those based on crime prevention strategies hinged on potential wrongdoers' ways of thinking and behaving. In order to do that, this study approaches female users' fear of crime of the London Underground in a more definite manner than preceding research. In general, the concept of fear of crime involves anxiety and fear towards criminal activities. Fear of anxiety may seem similar; however, they differ from each other. Fear is an emotion that accompanies perturbation and physiological and behavioral change triggered by impending danger whereas anxiety is a free-floating mood without forthcoming threat (e.g., Lang et al. 2000). For instance, feeling fear when awaiting a train standing next to a drunken stranger on an empty platform late at night, and being anxious to use public transport services after reading a newspaper article concerning violent crime, differ in nature and require different remedies. In this respect, a few decades ago, Garofalo (1981), a criminologist, divided fear of crime into 'actual fear' and 'anticipated fear' and suggested taking different approaches to them in order to alleviate each form of fear of crime. 
This study, in this vein, investigates 'actual fear' based on emotion appraisal theories in order to examine the situational influential features rendered by social, technical and physical conditions or resources of the service on female users' reasoning of fear. In the subsequent sections, accordingly, female users' fear of crime when using public transport services is conceptualized by tailoring the role of gender and public transport services to emotion appraisal theories. Based on the theoretical foundation, research methods for data collection and analysis and the results are presented. The findings of the present study are subsequently discussed in terms of the practical and theoretical implications and, lastly, the limitations of this study and directions for future research are presented.

\section{Theoretical background}

Cognition connects stimulus input and emotional responses, through processes named 'appraisal' (Moors et al. 2013). The cognitive mechanism is operated with subjects' personal conception and expectation of well-being, linking emotional responses to environmental circumstances on the one hand and personal goals and beliefs on the other (Smith and Lazarus 1993). In this section, the cognitive process of females' fear of crime on public transportation is conceptualised by integrating findings from the literature into a comprehensive whole in respect of fear appraisal, gender-based vulnerability and service elements.

\section{Fear appraisal}

An appraisal of threat accompanies fear (Ellsworth and Scherer 2009). First, stimulus is evaluated as being motivationally relevant and motivationally incongruent with a subject's desires or goals in the primary appraisal phase. Subsequently, the subject's coping potential towards the stimulus is evaluated as having low possibility in the secondary appraisal and, accordingly, fear is generated (Smith and Lazarus 1993). Centred on the theme of threat/danger and the relevant motivations, several appraisal components, such as novelty or low intrinsic pleasantness, have been proposed to account for fear in a more specific manner. The appraisal components of fear are categorised in Table 1 with examples which are probable in a context of public transportation. On the basis of these appraisal components, stimuli are evaluated and fear is engendered; these components distinguish fear from other emotions and anxiety.

The fear appraisal involving the subjects' goal and the relevant appraisal components is more comprehensible when compared with a general emotion process. Figure 1 depicts the fear appraisal components in association with an emotion information process. On the lefthand side of the figure, a generic model of emotion information process of Frijda (1986) is presented, leading down from 'stimulus event' to 'physiological change generators' and 'actor' through the phases of 'analyzer', 'comparator', 'diagnoser', 'evaluator' and 'action proposer'. In connection with these phases and the primary and secondary appraisal in the goal relevant dimension (Smith and Lazarus 1993), fear appraisal components of 'focality' 'low intrinsic pleasantness', 'novelty', 'insufficient coping potential' and 'urgency' are presented on the right hand side of the same figure.

According to Frijda (1986), when an individual confronts a certain event or circumstance, the stimuli or certain aspects of them are actively scanned and evaluated in terms of the subjects' various concerns in the phases of analyzer and comparator. Consequently, 'intrinsic attractiveness or averseness' which the situation may possess is evaluated 


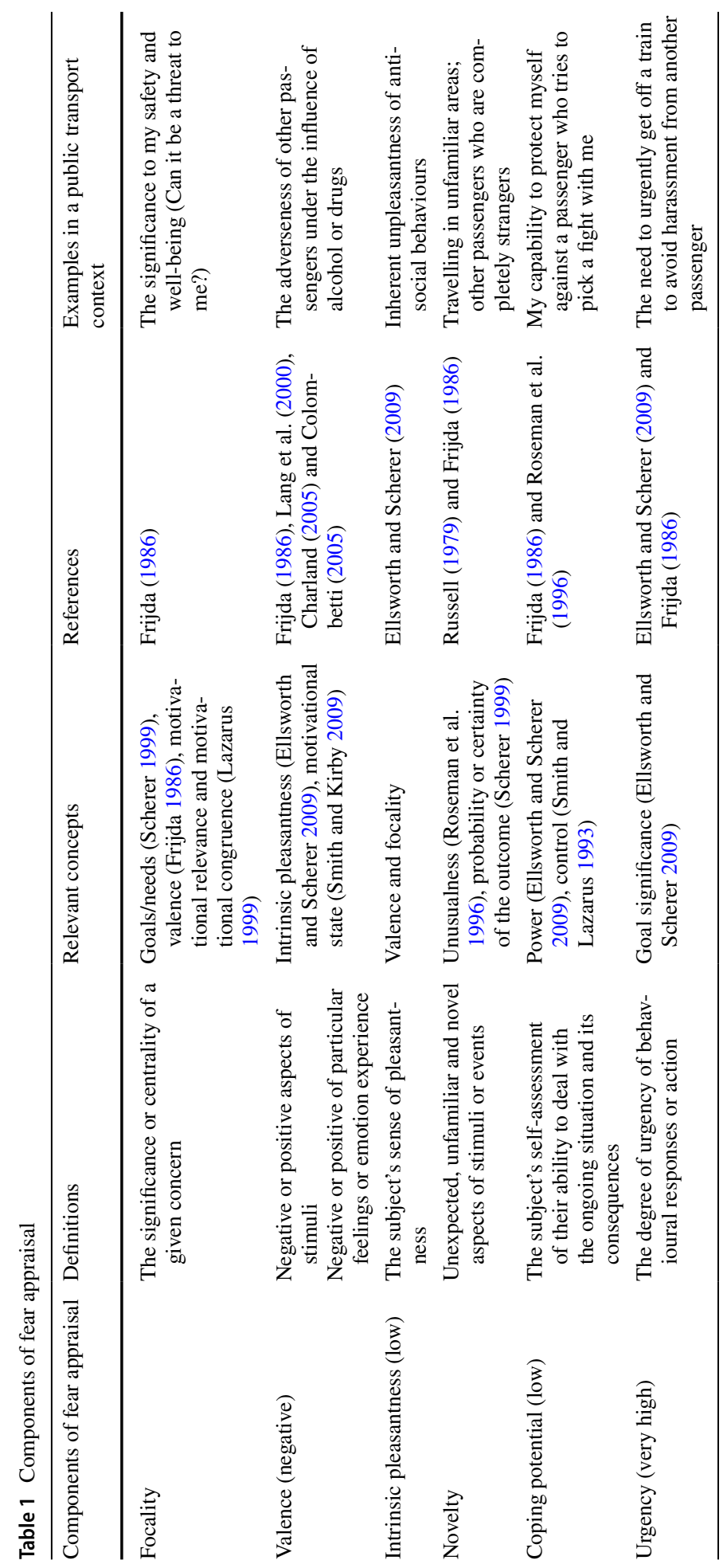




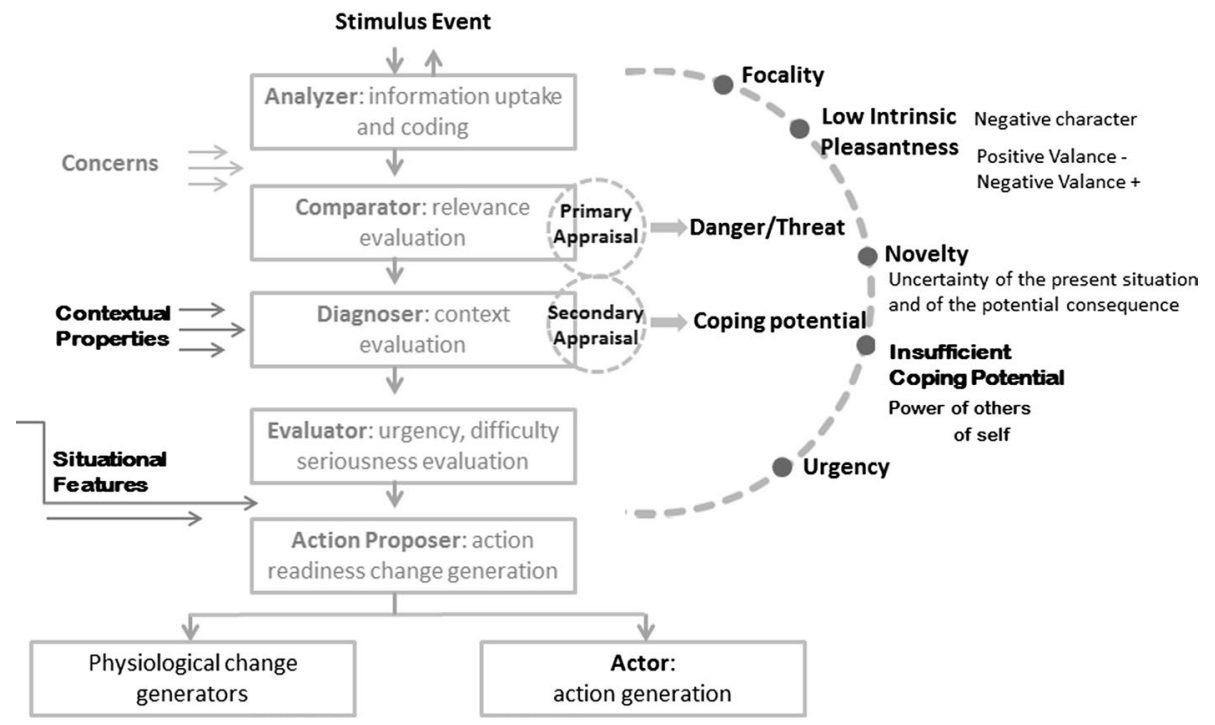

Fig. 1 Conceptualized process and components of appraisal of fear. Source: Frijda (1986) and Smith and Lazarus (1993)

according to a known type of the event and what it might imply to the subject, if possible (Frijda 1986). In the case of fear, stimulus is appraised as being intrinsically averse or negative as 'focality' is sensed in relation to the goal significance to subjects (Ellsworth and Scherer 2009). 'Novelty' and uncertainty concerned with the potential consequence of the event can also be seen in line with the evaluation of averseness (Russell 1979). For example, when using public transportation, a passenger being drunk and incapable can be sensed to be potentially significant to the subject passenger's safety (focality) and evaluated to be negative (negative valence and low intrinsic pleasantness). In addition, what he or she is going to do is uncertain and unpredictable (novelty). With these criteria, subjects evaluate a certain stimulus (e.g., the drunk passenger) as a potential threat or danger.

The diagnoser phase can be accounted for in a line with the secondary appraisal or the fear appraisal component of insufficient coping potential. Secondary appraisal is the evaluation of subjects' coping potential in relation to the potential threat (Smith and Lazarus 1993). In the diagnoser phase, in the same manner, the stimulus as a whole is appraised in respect of possibilities or impossibilities for coping. In this stage, the subject's contextual properties are utilized to determine which action is possible or not by combining prior experience of attempts to cope with similar or the same stimuli. Subsequently, in the evaluator phase, the degree of urgency, difficulties or seriousness of the stimuli is evaluated based on the information provided through the preceding phases. In the case of fear, the stimulus is evaluated as high urgency that requires immediate responses through the 'action proposer' stage (Frijda 1986). For instance, when the passenger who is under the influence of alcohol tries to pick a fight with the subject passenger, she evaluates the chance to win (coping potential) and urgently gets off a train to avoid a fight (urgency). Situational features or spatial contexts input into these stages and affect specific fear action generation. The outputs are generated accordingly: physiological and behavioural fear responses.

In addition to stimuli, there are additional inputs to the fear appraisal processes: concerns and 'side conditions' which are described as 'contextual property' and 'situational 
features' on the left side of Frijda's emotion process model in Fig. 1. The side conditions can be, in part, comprehensible in connection with 'facilitators on fear of crime' which refer to influential factors of fear including increased vulnerability or disorderly surroundings 'that lead a rational individual to be more or less fearful' (Franklin and Franklin 2009). In association with the contextual property and situational features, in the subsequent sections, the roles of gender and public transport services in the fear appraisal are conceptualised.

\section{Females' contextual property}

Prior studies on fear of crime in females have highlighted the group's perceived vulnerability to crime in explaining their greater levels of fear (e.g., Jackson 2009). In association with sex/gender, females' relatively weak physical strength and fear of sex-related crimes have accounted for females' high levels of perceived vulnerability to crime (e.g., Ferraro 1996; Loskela and Pain 2000; Pain 2001). It appears that females typically feel less able to fend off attack on the grounds of general beliefs such as they are less able to control risk and the consequences of the attack therefore could be more serious (Jackson 2009; Killias and Clerici 2000; Warr 1984). Moreover, females' risk of rape is shown to amplify females' fear of crime unlike males (Scott 2003; Loskela and Pain 2000).

Although females' vulnerability in previous studies, in general, denotes the group's general risk perceptions regarding crime and self when there is no evident threatening stimulus, it is also significant in fear appraisal. Emotion including fear is not a discrete event since the appraisal is affected by the subjects' previous experience, learning and beliefs as well as personality (Power and Dalgleish 2008). In order to process the information about stimuli, subjects need 'Contextual property', the coding categories for context and related knowledge (Frijda 1986; Smith and Lazarus 1993). In the case of public transportation, for instance, female passengers evaluate their vulnerability according to their knowledge about sex/gender, assigned to themselves, together with another contextual property related to stereotypes of offenders and space where crimes have taken place: strangers and public spaces. Although a majority of violence and sexual assaults against women are committed by acquaintances such as a friend or a family member in private spaces, women, in general, think it is the other way around (Madriz 1997). When using public transport services, therefore, females tend to think that they are more likely to be exposed to danger and, due to their sex/gender, they are less able to protect themselves and could be seriously injured. In this manner, female passengers can feel vulnerable and fear of crime even when encountering minor forms of threatening behaviours such as being followed, being leered at or being whistled at by strangers (Pain 1997). Thus, it indicates that females' sex/gender plays a role in evaluating their fear appraisal, providing a yardstick for judging their vulnerability in fear-evoking situations.

\section{Situational features rendered by public transport service design}

Service users experience services by interacting with service touch-points, the tangible elements of services (Clatworthy 2011; Shostack 1993). The interactions involve the service system, that is, all the available resources for the service including the service company's staff, users, organization/control, and physical/technical environment (Bitner 1992; Edvardsson and Olsson 1996). In this way, when feeling fear of crime on public transportation, users inevitably interact with these components of the service system. For instance, 
other users are shown to play a pivotal role both in easing and in evoking users' fear and anxiety. In addition, certain conditions of service environments in relation to a poorly managed environment or safety measures such as CCTV and security personnel are shown to influence users' feelings of safety (Yavuz and Welch 2010).

The social and physical factors in a certain condition affect users as fear evoking stimuli; in addition, the role of situational features in the fear appraisal process can also account for the influences of public transport services. Situational contexts or features mitigate or aggravate the emotional state of fear by affecting the subjects' behavioural responses (Frijda 1986). In terms of the mechanism of the situational features, in psychopathology, emotions are postulated as 'complex chains of events with stabilizing loops that tend to produce some kind of behavioural homeostasis' (Plutchik 1990). In the case of fear, until the threatening factor is dissolved and the emotional arousal is stabilized, the circumstances are constantly scanned and affect the selection of specific behavioural responses (Power and Dalgleish 2008). It indicates that certain features and configurations of public transport services may affect females' fear appraisal and the resultant behaviour by influencing the selection of specific actions.

\section{Methods}

Emotions are difficult to directly observe, measure or anticipate and, hence, enquiries into emotional phenomena are mainly dependent on the subjects' actual experiences and their diaries (Oatley et al. 2006). For the enquiry, therefore, semi-structured face-to-face interviewing is employed to facilitate eliciting narratives of females' experiences in the London Underground.

Taking the form of a qualitative approach, this study fundamentally conforms to the guidelines of 'grounded theory', a general methodology for developing theory that is grounded in data in a systematic manner (Strauss and Corbin 1997). In fact, it does not completely concur with conventional grounded theory studies since it is based on a more pre-structured format and, consequently, does not take the 'theoretical sampling' route. Contrary to Glaser's version of grounded theory (1992), which advise approaching the data without anything other than an open mind, prior to the inquiries, the group's fear of crime on public transportation is conceptualized based on existing literature. It is provisional until verified against data in the format of an 'abductive' inference which requires constant moves back and forth between data and existing theories for the best possible explanation of the researched phenomenon (Thornberg and Charmanz 2014). In this abductive manner, data were collected and analysed as a way to construct a more reasonable theoretical model.

\section{Interview strategies and questions}

Before conducting interviews, major interview questions and strategies are formulated. This enquiry is to gain live experience and cultural meanings within the underground service in the fear of crime context; therefore, the questions aim to facilitate eliciting narratives of interviewees' experiences. In order to derive narratives about the fearful experience of female users, the initial main question was: 
Could you recount any experience of fear of crime you have had as a woman while travelling on the underground in as much detail as possible?

Initially, the question was designed for delimited narratives into female specific fear of crime in the underground in order to access female fear appraisal in the underground setting. However, through a pilot study conducted with a female user in her $60 \mathrm{~s}$, a problem was raised; the question delimited the respondent's answer, linking to general female features and crime not to her own experience and feelings.

...I am vulnerable to sexual crime or mugging crime. I think... I guess actually you are more vulnerable as a woman on your own in stations I don't think it makes much difference in a mugging crime. I think you definitely feel more on your own because as a woman you are not as strong as most men and you do feel very wary if you are on platforms on your own because men are quicker than you if they try to catch you.

After she said she was vulnerable to sexual crime or mugging crime, she expanded it to all women's feelings and general physical differences between men and women, switching the subject to the interviewer, female. When asking the reason for the generalization after the interview, she answered that she did not feel vulnerable to or fear of sexual crime but she did feel afraid of being mugged. However, since the question was about fear of crime as a woman, she answered in that way, according to what she expected as what the interviewer wanted to hear as Fielding and Thomas (2008) point out as a common problem which frequently occurs during interviewing. As the pilot study revealed, asking fear as being a female can demarcate the answer, linking to their knowledge of gender and the relevant crime, not eliciting their experience of fear. Thus, more systematic elicitation was needed to be addressed.

In this respect, ethnographic question technique including descriptive, structural and contrast questions and free association technique were additionally employed for a systematic elicitation of latent thoughts. The interview questions are refined by two additional pilot studies which were conducted with a native user in her 20s and with a non-native Chinese user in her 20s who had used the underground service only a few times before finalizing the formats. The specific interview questions and the order are presented in the "Appendix" section.

\section{Data collection}

With the interview questions, but in a flexible manner according to the interviewee, face to face interviews with 31 female users of the London Underground were conducted, complying with the American Psychological Association Code of Ethics. These interviews were conducted at three different areas to address various experiences and travel patterns according to geographical differences: Oxford Circus (Central London, Zone1), Uxbridge (Zone 6), the terminal station of Metropolitan and Piccadilly lines, and Hampton Court railway station (Zone 6) where passengers need to transfer from a railroad train to an underground carriage to travel into Central London. The interviewees were recruited by the author and participated near those stations. Before conducting the interviews, each potential participant was adequately informed of the purpose and usage of the interview and the participant's rights, including the right to withdraw at any time without having to give a reason. After that, the interviewer asked the participant's approval for the interview. All interviews were audio recorded with permission from the interviewees and the whole audio-recoded 
data were transcribed. The data were gathered and simultaneously analysed until theoretical saturation occurred.

Although, consequently, 31 female users were interviewed, theoretical saturation, the point at which no new information or themes are observed in the data, occurred before reaching the thirty-first interviewee. This is accordant with the guidelines for adequate number of samples which suggests that basic elements for themes appear within the first six interviews and saturation occurs within the first 12 interviews (Guest et al. 2006) and six to eight interviews for a homogeneous sample and 12-20 to achieve maximum variation (Kuzel 1992). However, as well as sex/gender, individuals' perceived vulnerability has appeared to be affected by various factors such as prior crime-related experiences, age and race and cultural background (Crime Concern 2004; Killias 1990). In this respect, more interviews with women with various cultural background and age differences were conducted to address as much potential diversity within the phenomenon as possible. As a result, data in respect of female users' experiences and thoughts whose ages ranged from their 20 s to over 70 s were collected. The interviewees are composed of native users who were born and grew up in the UK, mostly in London, and non-native users who had stayed in London for a relatively short period of time from several months to 8 years as international students and foreign workers, who came from Eastern Europe, the Middle East and Northeast Asia.

\section{Data analysis}

In order to facilitate the data analysis, this study takes the coding method of Strauss and Corbin's version of grounded theory (1997) since (1) coding 'paradigm' offers a suitable and organizational scheme to analyse phenomena of fear of crime in the underground which involves conditions, context and consequence; and, (2) by selective coding, themes or concepts related to gender and the underground service can be analysed as the pivot of the phenomena without losing contexts. The analytic procedures are outlined as follows:

Step 1 open coding The transcribed data were line-by-line reviewed thoroughly and initially open coded. The chunks of data were divided into pieces and categorized according to similarities and differences with other codes, concepts and categories. Concepts and themes were named based on the interviewees' terminology or generally used terms in the culture as a form of 'in vivo coding' in order to minimize potential for bias.

Step 2 axial coding The initial codes were further categorized in terms of causal conditions (i.e., fear-evoking stimuli), context (i.e., active and background factors of fearevoking stimuli), intervening conditions (i.e., contextual properties and situational features) and action strategies (i.e., female users' behavioural responses) in relation to fear of crime.

Step 3 selective coding - themes of fear appraisal Among 'context' categories, active factors of fear-evoking stimuli, or the themes of fear appraisal were further analysed as a core category. The concepts were refined by being constantly tested against collected data and pre-existing theories on fear appraisal and by relating with other categories such as 'background context' which involves temporal and geographical factors and 'fear behavioural responses'.

Step 4 selective coding - the role of sex/gender In order to examine the role of sex/gender in the fear of crime context, the category of 'contextual properties' of intervening conditions was put on the central axis. The sex/gender related factors such as 'female 
physical vulnerability' or 'perceived vulnerability towards rape' were further examined by relating with 'themes of fear appraisal', 'fear behavioural responses' and individual and social variables such as individual characteristics, age, cultural background, cultural assimilation and geographical differences.

Step 5 selective coding - the influence of the underground The categories of 'situational features' were further examined as the central axis in connection with 'themes of fear appraisal' and 'fear behavioural responses' involving 'defensive immobility', 'gravitation towards others' 'flight', 'fight' 'fright' and 'seeking help'.

Throughout the coding processes, memo writing, constant comparing and sorting and diagramming memos were used in a way to support the analytic process. In order to facilitate the constant comparison between codes, concepts and categories and to remain readily auditable back to the transcripts, NVivo, the qualitative analysis package, was used in developing and linking codes and the relevant texts in transcripts and notes. The themes and variables and their relationships which emerged during the coding processes were constantly tested against data, comparing existing theories in order to find the best possible explanations.

\section{Results}

\section{Themes of fear appraisal}

Fear-evoking stimuli in the underground appear to be initially evaluated in terms of negatives and positives (valance) and familiarity. For instance, during the interviews, certain groups of people were frequently mentioned as strong fear-evoking stimuli due to their features and behaviour which the interviewees perceived as being negative.

... and I saw a teenage group on a train. They used a carriage as if the carriage was theirs, talking very loudly. I was in the next carriage but their voices were so loud that they could be heard even in the next carriage. Seeing them was also scary because I thought that if I made eye contact with them, they would follow me (non-native user, 30-39).

Although individual distinctions appear in perceiving a certain group of people as a threat, what evokes female users' fear of crime appears the same as that manifested in aggressiveness and anti-social behaviour as in the interviewee's account above.

In addition to the negative valence the fear evoking people have, the absence of positives in certain situations is shown to influence female users' fear appraisal.

Sometimes there are only a few numbers of users on the station and I get really scared because of the fact that I am alone. Because I am all alone I could be an easy target for someone awkward and when someone tries to harass me, it could be very difficult to ignore or confront him or her by myself (non-native user, 20-29).

The quotation above exemplifies the absence of positive valence; when there are few or no people around the subjects, they tend to perceive the situations to be negative. When 
subjects perceive there is no potential help, in case of a threatening situation emerging, it is shown to evoke fear even if there are no threatening factors around them.

When the users do not have enough knowledge or experience to appreciate the negatives or positives of stimuli or environments, it is shown to affect the subjects' anxiety and fear. The theme of unfamiliarity was observed in the interviewees aged over 60 and non-native interviewees who had lived in the UK for a relatively short period of time. In particular, unfamiliarity with other users in the service environment appears to significantly affect non-native users' fear of crime as an interviewee described:

I feel like... some people here I do not know why, but here people keep looking at me. Mostly men... I feel a bit afraid ... So I feel afraid of them sometimes. They just look scary they are strong and tall. If they want to do something to me they can do it... I am afraid (non-native user, 20-29).

The themes of valence and unfamiliarity appear to be appraised in association with certainty or probability of the outcome. Fear of unpredictable people such as individuals whose behaviours are suspicious and those who are under the influence of alcohol or drugs exemplifies the theme of uncertainty.

...sometimes I notice people who behave in a strange way. They are unpredictable... maybe he can have a knife in his pocket but it's only my imagination. Nothing ever happened ... people who are under the influence of alcohol or drugs are scary because they are unpredictable (non-native user, 20-29).

When the effects have not fully materialized, the probability or certainty of potential effects appears to be as significant as the event or situation itself. Uncertainty of the outcome of situations appears in conjunction with appraisal for controllability over the situations and potential outcomes in association with female users' coping potential as in the interviewee's account below:

I was waiting a train at late night, and three guys come to me... I saw they were carrying knives. They might have killed me or taken away my money. Maybe... they would have not killed us but hurt us with knives. ... I am a lady and they are three guys and they were carrying a weapon, knives. I did not have anything to protect myself (non-native user, 30-39).

When confronting potential threats, the subjects are shown to evaluate themselves compared to the threat in terms of power, such as "a lady" versus "three guys who are carrying a weapon" as the interviewees, above, described.

To sum up, themes of fear appraisal are identified as 'valence', 'unfamiliarity', 'uncertainty' and 'uncontrollability'. In this study, 'focality' and 'intrinsic pleasantness', the presupposed themes of fear of crime are incorporated into 'valence' which refers to the positive or negative charge of stimuli and the service environment. Moreover, 'novelty' is divided into 'unfamiliarity' as the absence of knowledge or experience to evaluate positive or negative valence of stimuli, and 'uncertainty' as unpredictability of future events which the stimuli may lead to. While 'unfamiliarity' is a stimulifocused evaluated theme with 'valence', uncertainty is defined as a theme evaluated in relation to self and stimuli, or coping potential. Therefore, in a more specific manner, 'insufficient coping potential' is segmented into 'uncertainty' and 'uncontrollability' which indicates lack of subjects' capability of modifying or influencing the course of events and its potential consequences. The results are presented in Table 2. Therefore, from the findings, a proposition was derived as follows: 


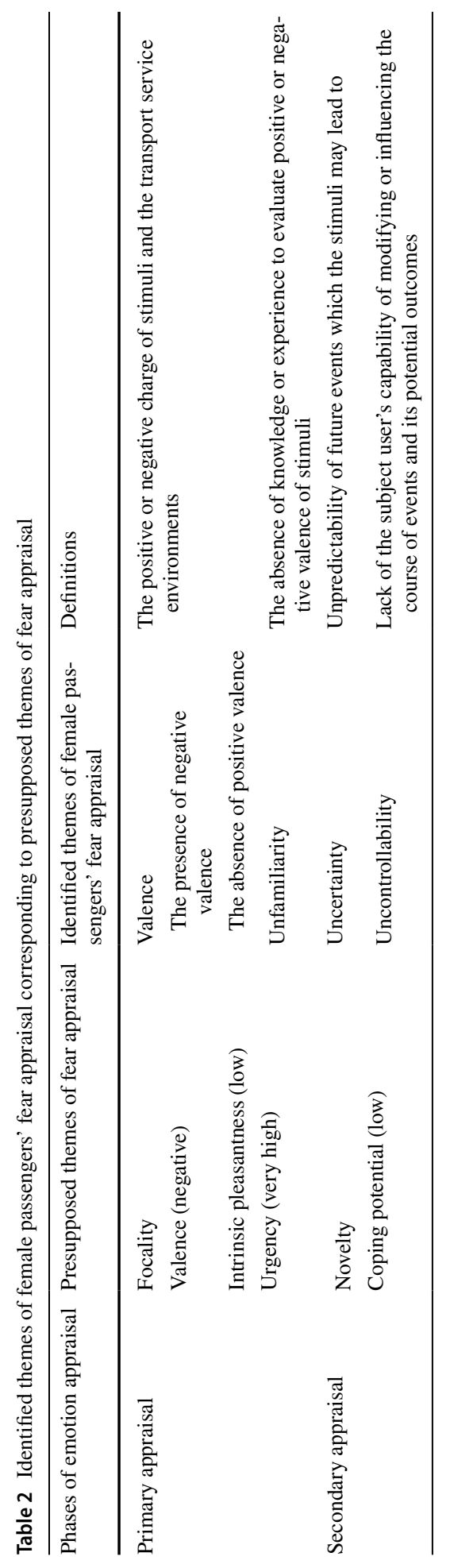


Proposition 1 A female's fear of crime is engendered according to 'valence' and 'unfamiliarity' of primary appraisal and 'uncertainty' and 'uncontrollability' of secondary appraisal.

\section{Perceived vulnerability as a woman}

In previous studies, 'shadow of sexual assault', the negative effects of females' exposure to sexual assault have largely accounted for females' heightened vulnerability and anxiety (e.g., Ferraro 1996). In the underground, however, female users' perceived vulnerability is, in general, shown to be affected by their physical strength but not significantly by concerns or worries about sex-related crime. The discordance in respect to perceived vulnerability towards sex-related crime can be, in part, accounted for by the natural and designed surveillance of the underground service which female users perceive. As the interviewee, below, described, female users' general perception of the underground as crowded or open spaces are, in general, shown to diminish their perceived vulnerability to rape.

... Obviously, everyone feels fear of being raped. I wouldn't especially feel fear of being raped in the underground because simply there are so many people around whenever I'm there. So I think my fear of being raped would be much more heightened if I was out working and I was exposed in that way rather than in the underground (native user, 30-39).

However, when they perceive themselves as being in vulnerable situations, such as being alone on an outside platform at night, concerns about sex-related crime is shown to affect female subjects' fear appraisal to some extent. In such a vulnerable situation, a female user is shown to tend to perceive herself as a woman with weak physical strength as interviewees described themselves as "a lady", "Asian woman" or "old woman". In addition, it appears that the more a female user perceives herself as being vulnerable, the more likely she is affected by fear of sex-related crime. The interviewee's description about her experience, below, exemplifies how fear of rape emerged in conjunction with subjects' deficient resources for coping with fear evoking events.

...I thought I could be mugged or be raped. I felt slight fear a couple of times on the underground before but I had never worried about being raped until then...but I did not know what's going on and what's going to happen to me. I would ask for help if there was anyone I could call for help. There was no one I knew in London at that time (non-native user, 20-29).

As she narrated, together with the situational uncertainty, her sense of uncontrollability resulting from the lack of resource for coping is shown to aggravate the subject's fear of sex-related crime.

The lack of resource for coping appears to be related to individual and social characteristics that subject female users have. For instance, the majority of the non-native interviewees who had stayed in the UK for a relatively short period of time expressed intense anxiety and fear of crime in conjunction with a lack of social connections, as in the interviewee's experience, above, and unfamiliarly, or lack of accumulated knowledge to appreciate situations. 
... After reading that kind of story, it is too scary to use the underground. I know that it could be just a rumour and not testified... but I came here just months ago and I cannot speak English very well so... (non-native user, 30-40)

As in the account above, concerning the interviewee who came to the UK 4 months before the interview, the length of residence and language proficiency are shown to affect female users' fear in association with the lack of confidence in dealing with situations and the potential outcomes. This is contrary to a native user's account, below.

It's to do with body language and I believe my body language says I'm not worried and I know where I'm going so there is no hesitation in what I'm doing. I was born, grew up and lived in London all my life. I work with men on construction sites so... I have appropriate body language which says don't mess with me...if you are not a confident person, you are gonna find fear in a lot of places unfortunately. (native user, 40-50)

Unfamiliarity also appears among native interviewees aged 65 and over (defined by WHO 2013, as elderly) who described the underground stations as "disorienting" or "too big" and, thus, fear-evoking, even though most of them have used the underground their whole lives. In the case of the native interviewees with ages ranging from 20-65, who irregularly use the underground or usually use other transportation modes, unfamiliarity also appears; however, their unfamiliarity with the underground service does not significantly affect their fear of crime in the underground.

In addition to unfamiliarity, racial differences appear to affect self-evaluation in respect of gender and their vulnerability to criminal activities. Certain Korean and Chinese interviewees expressed more intense anxiety in the underground and vulnerability due to their physical strength and body size which they evaluate as being weaker and smaller than other females from different races, as well as males.

Well... I am a woman and I am abroad. Because I am an Asian woman, I am physically weak. I've never thought that other woman or Asians would think of me as an easy target but compared to men, if I were a man, I would feel less fear. ... I think that Asian women are physically weaker than even white women and I am not tall. I am short and small so they could think of me as an easy target ...

Along those lines, a lack of social resources, unfamiliarity due to the length of residence, language proficiency and age and perceived physical disadvantage caused by racial difference are shown to influence female users' anxiety and fear of crime in relation to a deficiency of resource for coping.

To conclude, fear or concern about rape appears not to be prevalent in the underground; however, it appears to emerge in vulnerable people in vulnerable situations. Along with individual resources for coping, female users' physical strength and, contingently, worries about sex-related crime are shown to influence their perceived vulnerability and the themes of secondary fear appraisal: uncertainty and uncontrollability. Users' individual and social characteristics related to the degree of social assimilation, age and self-evaluation appear to play roles as the resources for coping and, accordingly, influence fear appraisal. Thus, the following proposition was derived:

Proposition 2 Females' vulnerability caused by their sex/gender influence the subject's secondary appraisal, interacting with the subject's resource for coping potential. 


\section{Influential situational features of public transport services}

\section{Perceived availability of staff/metro police}

The presence of people in authority in the underground appears to significantly affect female users' feelings of safety and fear of crime. Their presence in situations is shown to play roles of reassuring the users as potential help and potential deterrence against criminal activities as the female users described below.

Sometimes I can see staff wearing TFL clothes. When I see them for example drivers going home, I feel safer. They are staff working here to take care of things like police men (non-native user, 30-39).

...I mean I would guess their presence makes it being safer... I think the police presence even in this day and age is a deterrent. Not as much as it used to be. But it makes somebody else think twice (native user, 40-49).

However, the positive effects of service staff and metro police appear to be contingent on their availability that users perceived in fear-evoking situations. In this context, their visibility in fear evoking situations is shown to be significant.

... I don't think the guards would make me safer as long as they're not obvious they are guards ... (native user, 70-79).

...I can be very cynical about the police force for somebody married to one, you never know where they are or where they're going or what they're doing (native user, 40-49).

As these interviewees point out, the absence of discerning factors such as uniform and their unpredictable locations appear to negatively influence the visibility of service staff/metro police from the service users' perspective. Subsequently, the insufficient visibility negatively affects female users' perceived availability of service staff/metro police who could intervene in fear-evoking events.

Compared to the presence of service staff and metro police officers, technical equipment in the underground such as CCTV and help-points are viewed somewhat sceptically by female users who consider these unhelpful when in actual immediate danger.

It's useful if it is evidence but if you are in danger... Whoever monitoring it is too far away to be of any useful help (native user, 60-69).

CCTV shows what happened and how the incident happened but cannot protect people at the time. It is better if there are CCTVs than nothing being there. (native user, 50-59).

No, (laugh) because no idea who the person is that's answering you. No, if not sure where they are and there's no one on the station it's such a stupid method (native user, 70-79).

Well... if it is not broken, it would be helpful. But it is like CCTV. If there is guarantee someone will come to help me and it is well managed... but even in a lift, when it stops working, you know, they do not always work even when I accidently push the button. So I cannot trust it. (non-native user, 30-39). 
As the interviewees described, female users appear to perceive the effectiveness of CCTV and help-points to be limited in fear-evoking situations. Their perceived accessibility to immediate help appears to be impinged upon by the unknown distance between the passengers and available help and no guaranteed immediate response from people in authority who monitor CCTVs and answer help-points. The perceived inaccessibility to service personnel and metro police, consequently, negatively influences the subject users' perceived availability of staff/metro police as a potential intervention and deterrent for violent crime.

Along these lines, in connection with perceived availability of potential help, visibility and perceived accessibility to service staff and metro police appear to affect female users' secondary fear appraisal. Since they operate in relation to potential help in situations, when these service attributes are deficient, it appears to affect users' fear of crime by negatively affecting subjects' evaluation of their coping potential. Thus, in association with the social and technical condition, perceived availability of service staff/metro police is identified as an influential factor on female users' fear appraisal, with its attributes of visibility and perceived accessibility to service personnel. From the findings, the following proposition was derived:

Proposition 3.1 Perceived availability of service staff/metro police consisting of visibility and perceived accessibility influences female users' fear of crime by affecting their sense of uncontrollability and uncertainty in the presence of fear evoking stimulus.

\section{Spatial and technical accessibility and spatial visibility}

Certain physical environmental features of the underground also appear to affect female users' secondary appraisal, playing a pivotal role in generating the immediate defence behaviour such as the 'flight' response or 'gravitation towards others' and in stabilizing the subjects' emotional arousal. First, spatial configuration of the underground appears to create limited spatial accessibility to escape as typified by being in a carriage. It is shown to affect users' sense of being confined and block the response of 'flight', the typical action tendency of fear.

And on the underground, if something happens there is no way to escape. Bus is different because it is on the ground. Because if I am on the bus, I can escape if anything happens... (non-native user, 20-29).

...So in order not to get their attention, I did not move and looked down, looking at my hands to avoid eye contract with them...until getting off at the next stop. I thought that if they paid attention to me, I would be dead. (non-native user, 30-39).

As the interviewees above described, once female users enter a train, they have limited control over situations; moreover, their movements are constrained in a carriage till the next stop. In this manner, as specifically appeared in the interviewee's experience, above, the temporarily blocked or withheld escape appears to aggravate fear arousal with uncertainty and uncontrollability over the situation. In addition to limited spatial accessibility to escape, the physical features of a moving carriage also appear to create openness to potential threat. The opened spatial accessibility for potential threat is shown to affect female users' feelings of safety and fear as described below: 
And even when I am all alone, the carriage's doors continue to open and close... so until someone who looks safe gets in the carriage, I would be uneasy. Travelling alone is okay but some dangerous man could get on at any minute. That is scary. (non-native user, 30-39).

In addition to the spatial accessibility limited to escape and being open to potential danger, technical accessibility to other people also appears to affect female users' anxiety and fear in the underground. In certain platforms and in moving carriages, using a mobile phone or technical equipment which connects users and service personnel or people outside the underground appears to be limited and impractical. The disconnection is shown to link to the feeling of being isolated from the potential help and outer world.

Because the London underground does not have a signal I mean the signal of mobile phone. I don't like it. If you meet something fearful, you cannot connect to the outside world so this makes me uncomfortable. I do not like it I want ... if I meet something I fear of, I want to directly contact to my friend or somebody (non-native user, 20-29).

If they could do something which would allow you to have telephone reception that would be kind of helpful because it is one of the things most frightening, being so alienating. You do feel if something happens you have no way to contact to your family to say... you know... "you may have seen there's a bomb down there, I'm fine I'm just down here. I'm just waiting to be allowed to come up" The fact you can't do it makes it more frightening. (native user, 30-39).

The former interviewee, above, displays a tendency to seek a sense of emotional stability by connecting to friends or family, while the latter expresses altruistic fear for her family in connection with terrorism. Although the contexts are slightly different, their anxiety and fear appears to be linked to the technical inaccessibility to the outside world.

In addition, spatial visibility of the outside platform at night also appears to be a fear-evoking stimulus and affects uncertainty regarding potential danger.

...because everything is exaggerated at night anyway. You can't see as clearly as you can see in the day. And also the lighting in the underground station is very poor. It's not light... it's quite dim. And so you are not sure if you are seeing things clearly because you have feelings of fear, you can imagine things too (native user, 70-79).

I use the underground only within Central London so... lighting is not a problem. But I have a friend who lives far away from central London. I visit her quite often. I think the station is quite remote... and it is dim at night. When there are no people at night, it is quite scary. (non-native user, 20-29)

As apparent in the interviewees' accounts above, in connection with travelling time and geographical variables, limited spatial visibility caused by dim lighting appears to affect female users' fear appraisal.

To sum up, the physical environment of the underground is shown to impinge upon female users' certainty and controllability and consequently, fear of crime, by configuring accessibility limited for female users and being open to potential danger, technical inaccessibility to potential help and outside and spatial visibility. Accordingly, the following proposition was derived: 
Proposition 3.2 In terms of physical environmental features, spatial and technical accessibility to other spaces and potential help and spatial visibility affect female users' themes of secondary fear appraisal: uncertainty and uncontrollability.

\section{Reliability of service}

Reliability of service is identified as another influential factor on female users' fear appraisal. Inaccuracy of the service such as stopping vehicles during the operation appears to significantly affect female users' feelings of safety in conjunction with fear of terrorism.

I feel the most fear when there are strikes especially during the rush hour; without giving any proper notice why there has been a strike. We know from that London bombing 2007... (non-native user, 20-29).

Fear of terrorism appears to be widespread in the London Underground as many interviewees, including the interviewee above, expressed terrorism as evoking the most fear in the underground; in addition, stopping the vehicle between stations, without proper information, is shown to provoke the subjects' fear of terrorism.

Moreover, when female users are situated in fear-evoking events in vehicles, delays between stops appear to aggravate the subjects' fear arousal as exemplified by the interviewee's narrative below.

... the men came round us surrounding us jeering and making very crude gestures and we were both very scared. We just talked to each other and ignored them but they were very much in our space... we were both so frightened... and there is a stretch on the Piccadilly line when they are no stops for ages. And it really seems ages and... (native-user, 60-69).

The inaccuracy of the service is shown to affect female users' uncertainty and uncontrollability over the situation by protracting the connection with fear-evoking stimuli on the carriage and the disconnection with other influential factors of 'perceived availability of staff/metro police' and 'spatial and technical accessibility' to escape and potential help. In connection with service reliability, in this manner, accuracy of service and sufficient information appear to affect female users' fear of crime. Therefore, from the findings, the following proposition was derived as follows:

Proposition 3.3 Reliability of service involving accuracy and sufficient information affects female users' feelings of uncertainty and uncontrollability.

All the influential situational features of the London Underground are categorized in Table 3 with the definitions.

\section{Discussion}

\section{Conceptual model for understanding female passengers' fear of crime}

On the basis of the propositions, in Fig. 2 a conceptual model for understanding females' fear of crime in public transport services is proposed. 
Table 3 Influential situational features of the London underground

Perceived availability of staff/metro police

Users' perception of being able to obtain prompt help from the service personnel or metro police in the presence of fear evoking stimuli

Visibility of service staff/metro police

The state of being able to see and recognize people in authority in the underground service, such as service staff and metro police, when encountering fear-evoking stimuli

Perceived accessibility to service staff

Approaching service staff for help when users need it but there is no visible service personnel

Spatial accessibility

The state of being able to enter or move from one space to another

Spatial accessibility to escape

The state of being able to escape from situations via secured escape routes naturally configured by service environment

The openness to potential threat

The features of the service which the public including potential wrongdoers is given access to

Technical accessibility

The state of being able to connect to others and the outer world, using technical equipment or devices Spatial visibility

The state of being able to see clearly without blind spots, or uncertain sections of darkness beyond and behind individuals' sight

Reliability of service

The dependability of the service which involves the consistency of the service in transacting as scheduled and in providing appropriate information

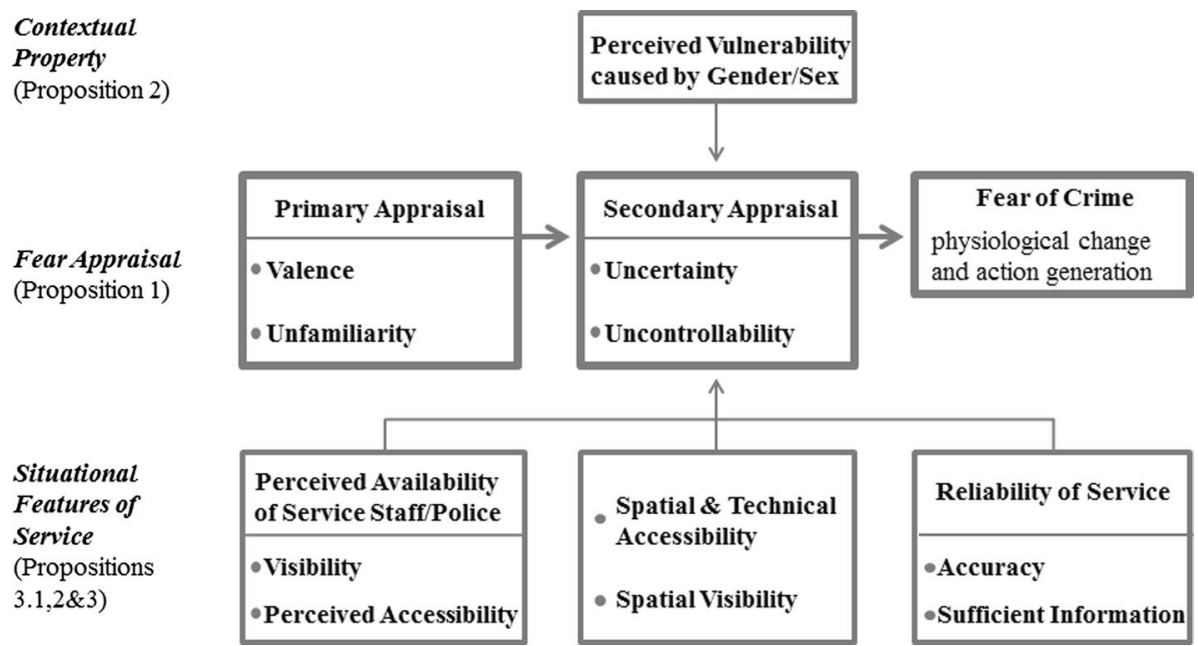

Fig. 2 A conceptual model of females' fear of crime in public transport services 
It is divided into largely three parts: (1) fear appraisal, (2) contextual properties, and (3) situational features of public transportation as pre-conceptualized based on existing literature, each of which is associated with Propositions 1, 2 and 3.1, revealed by the interviews. In this model, in relation to Proposition 1, there are two categories that cause fear of crime, named 'primary appraisal' and 'secondary appraisal', comprised of four themes of fear appraisal: 'valence', 'unfamiliarity', 'uncertainty' and 'uncontrollability'. As in Proposition 2, perceived vulnerability based on gender/sex influences the secondary appraisal as a contextual property in evaluating females' coping potential against fear-evoking people or events. In addition, three categories labelled 'perceived availability of service staff/police', 'spatial and technical accessibility and spatial visibly' and 'reliability of service' are presented, as being influential factors of public transport services on the themes of secondary fear appraisal, reflective of Propositions 3.1, 3.2 and 3.3.

These influential factors are presented as being mutually exclusive in the conceptual model; however, they are, rather, interrelated with each other. Reliability of service (Proposition 3.3), for instance, is concerned with perceived availability of service staff/police (Proposition 3.1) and the physical environment related factors (Proposition 3.2). When service is unreliable, it appears to affect female users' fear of crime by protracting the disconnection between a subject and those influential factors of the social, technical and physical conditions in the presence of fear evoking stimuli. Furthermore, the physical environmental factors (Proposition 3.2) are shown to significantly influence female users when they perceive there is no available potential help from service staff/metro police (Proposition 3.1) or other passengers. In this study, these critical and interrelated influencers are shown to affect the themes of secondary appraisal and, subsequently, fear of crime, operating with the subject's perceived vulnerability as a woman. These findings indicate that by effectively managing those attributes, females' fear of crime can be ameliorated.

\section{Design guidelines for public transport services}

\section{Service staff and police}

In the context of females' fear of crime, the activities of service employees and police are shown to be related to the role of reassurance, by enabling the subject users to regard people in authority as available in case of danger. In this respect, their visibility in the service environment should be reinforced by increasing patrols and by enhancing the discerning factors of service staff, such as uniforms. Moreover, the relevant information such as those regarding surveillance and locations where staff or police officers could be positioned should be adequately communicated. By extension, surveillance should be designed and managed in a way to supplement the environmental conditions that fluctuate as a result of geographical, spatial and time variables.

\section{Technical equipment}

In designing and applying technical equipment or devices which connect users to service employees or police, enhancing users' anticipated responsiveness from the people in authority should be primarily taken into account. For the effectiveness of such equipment as CCTVs and help points, the distance between users and people in authority should be designed to be close in proximity and transparent from the users' point of view. Prompt responses from staff or police officers, in addition, need to be guaranteed by expeditiously 
reacting to users through constant monitoring and immediate response. The relevant information should be communicated by visual displays, aids and broadcasting.

\section{Spatial and technical accessibility and spatial visibility}

Spatial inaccessibility to escape during the service is an underground-specific influential factor concerning female passengers' fear of crime, which is difficult to enhance in a short period of time, in particular, in the case of a developed service system such as the London Underground. Thus, social and technical elements of service need to be designed in a way to complement the restriction and female users' feelings of being insecure due to openness to potential danger. In parallel, the physical configuration of the underground, which constrains users' movements, gradually needs to be enhanced in the long term. Specifically, in the case of the London Underground, in addition, technical accessibility should be reinforced by enabling passengers to use mobile phones and Wi-Fi in moving carriages and all stations in order to decrease users' feelings of disconnection from potential help and to facilitate female users' tendency to seek a sense of emotional stability by connection to friends and family members. Additionally, spatial visibility of remote outside platforms, stations and bus stops needs to be enhanced to decrease female users' sense of uncertainty.

\section{Service reliability}

In delivering and managing public transport services, providing reliable services and appropriate information through broadcasting according to situations need to be considered on a preferential basis. Fundamentally, the service needs to be reliably operated as scheduled and without errors or delays. When inaccuracy unavoidably occurs, prompt information about the cause of the delay and service recovery time should be given to users. Public transport services, in this manner, should be transparent and predictable from the users' point of view to decrease users' situational uncertainty and feelings of uncontrollability.

Since the findings of the present study are based on the diagnostic information derived from the existing underground service, certain findings, in particular the physical environmental factors are restricted to the London Underground or, by its extension, underground services in other cities to some degree. In addition, the influence of service reliability on female passengers' fear of crime is also somewhat limited in the London Underground service since it appears to affect female users' fear appraisal in conjunction with their fear of acts of terrorism which have previously occurred in the London underground and the spatial inaccessibility to escape moving carriages.

Influential factors in respect to people in authority, technical equipment and service reliability, on the other hand, can be more broadly applicable to other modes of public transportation with the benefits of information communication technology, applied to personal devices. Currently, texting or making a phone call when witnessing something or someone suspicious and when being in dangerous situations is encouraged by transport agencies and police forces in many cities. For instance, the campaign "See Something Say Something" has been running in the United States, particularly in response to terrorism and the campaign "See It. Say It. Sorted." has also been used to encourage train passengers to report unusual items or activity in the United Kingdom. In addition, as a continuing effort of security campaigns, many transport agencies use smartphone apps as a reporting method for passengers (e.g., 'SEPTA Transit Watch' in Philadelphia, 'MBTA See Say' in 
Boston and 'LA Metro Transit Watch') so that passengers can easily and discreetly report suspicious activity directly to the police by sending pictures and text messages. Although those efforts are mainly to prevent crimes, if the related service is reinforced in a way that could increase female passengers' perceived availability of people in authority and service reliability, fear of crime could also be alleviated. In order to do this, transit agencies should make use of smartphone apps as a more active communication tool not limiting the function in gathering information about criminal activities. As a part of the efforts, efficient communication regarding surveillance and nearby location where staff or police could be found from the users' location can be undertaken. More accurate real time information about the transport services could also be given to users to make the service more transparent and predictable from the users' point of view by means of smartphone apps.

\section{Theoretical implications}

The present study suggests a way for public transportation design to manage female passengers' fear of crime, separated from design strategies for crime prevention. Basically, design for crime prevention aims to create a deterrent towards potential offenders to promote risk perception (Crowe 2013; Newman 1972). On the other hand, the findings of this study suggest that design of public transport services should also aim to decrease female passengers' sense of uncertainty and uncontrollability in order to address fear of crime. The difference in standpoints derives a more befitting design guideline to ameliorate female passengers' fear of crime.

In fact, certain design concepts of crime prevention appear to be effective to some extent. For instance, natural and designed surveillance of the underground appears to reduce female users' concerns about rape; as Newman (1972) suggests, natural surveillance functions in reducing fear by making people feel under constant observation by others. In the case of surveillance via closed-circuit television, however, the effectiveness appears to be limited which is contrary to design guidelines for crime prevention which suggests CCTV may diminish fear of crime (e.g., Reed et al. 2000; Cozens et al. 2004). Female passengers appear to consider CCTV as evidence to prove crime or to catch offenders after committing a crime and, therefore, such technical equipment is shown to be limited in easing female passengers' fear arousal in the presence of fear evoking stimuli in public transportation.

In addition, in the case of crime prevention, basically, the concepts of 'surveillance', access control' and 'target hardening' purpose to enhance the image of the built environment (Newman 1972). The enhanced image of the environment leads to more frequent use of the spaces and subsequently increases surveillance, again creating a virtuous circle (Reynald and Elffers 2009). In the case of public transport services, however, some of the design concepts such as 'access control' or 'target hardening' are difficult to apply or, in some cases, impracticable since they are conceptualized based on commercial buildings, industrial properties and dwelling areas (Crowe 2013; Colquhoun 2007). In fact, the openness to potential threat appears to negatively affect females on public transportation as well impinging upon the subjects' sense of certainty. However, such restrictions embedded in public transport services cannot be eliminated at once and, hence, need to be complemented by other service elements such as service employees, metro police and technical equipment in a holistic manner.

To conclude, although some of the findings may be limited to the underground service, the distinctly considerable factors to address female passengers' fear of crime constitute 
empirical evidence underpinning the need for an independent approach towards fear of crime for public transport services to ameliorate the social problem in parallel with the present efforts to prevent and reduce crime itself.

\section{Directions for future research}

By extension of the conceptual model, several research domains are suggested. First, the findings involve limitations in qualitative research as the results of a grounded theory in general, are considered to be dependent on context and not completely final (Thornberg and Charmanz 2014). Thus, quantitative testing and verifying the model with large numbers of female passengers would be desirable to conduct further research. In addition, since this study investigated only female users the findings cannot include male users and the influential factors of the service design and the attributes of the factors may, therefore, affect females and males differently. Moreover, the underground has a distinctive service interface and structure when compared to other modes of public transport services. In this context, the comparisons between the underground service and other modes of transportation were frequently drawn during the interviews. Thus, it can be difficult to generalize into males and all modes of public transportation and researching into distinct characteristics of male users and other modes of pubic transportations in relation to fear of crime would be beneficial.

The fortified set of the practical perspectives should enable service designers and policy makers to gain a better understanding of service design which alleviate passengers' fear of crime and, consequently, make an attempt at enhancing the well-being and quality of lives through public transportation.

Authors contributions The author, HK solely conducted the study including literature review, data collection and analysis and has written the manuscript.

\section{Compliance with ethical standards}

Conflict of interest The author states that there is no conflict of interest.

Open Access This article is distributed under the terms of the Creative Commons Attribution 4.0 International License (http://creativecommons.org/licenses/by/4.0/), which permits unrestricted use, distribution, and reproduction in any medium, provided you give appropriate credit to the original author(s) and the source, provide a link to the Creative Commons license, and indicate if changes were made.

\section{Appendix: Interview questions}

Free association questions- to understand the meaning of fear to the subject

Q1) "Can you think of something that you've read, seen or heard about recently, anything that made you feel afraid?" Could you tell me whatever comes into your mind. (not necessarily about the underground service) 
Structural Question (Free association)

Q2) "What do you most fear when using the underground?"

Typical Ground Tour Question (for a description of how things usually are)

Q3) "Could you describe your typical journey using the underground?" "When and where do you regularly use the underground and why?"

Mini-Tour Question (specific)

Q4) "Have you ever felt fear of being involved in crime in the underground?" "How often do you feel that kind of feeling?"

Q5) "Could you describe how that feeling affects your use of the underground?"

\section{Example Question}

Q6) "Could you tell me about any fearful situations you can think of to do with using the underground?"

Free association

Q7) "Imagine that you are in a situation, what would you do to resolve the situation? Could you tell me whatever comes into your mind"

Q7-1) "Have you ever hesitated or been passive in dealing with fearful situations? If so, why?"

\section{Experience question (Descriptive Q)}

Q8) "could you recount any experience of fear of crime you have had while travelling on the underground in as much detail as possible? From the moment you decided to use the underground until the feeling went away?"

Q8-1) What did you think that you could be a target of the crime? why did you think that you could be in danger?

Q8-2) Why did you think that you were not able to protect yourself?

Q8-3) What was the worst scenario you experience of being involved in the situation?

\section{Contrast Question}

Q9) "Do you think you are more vulnerable to crime in the underground compared to a male traveller? What makes the difference? What do you think makes you vulnerable?"

Q9-1) Do you think you are more likely to be a target of crimes? Compared to male travellers.

Q9-2) Do you think you are not able to protect yourself?

Q9-3) Do you think when you are involved in crime or such the trouble you told before the consequence would be more serious than men?

Q10) "Females have been shown to be much more exposed to sex-related crime such as sexual harassment and rape. Research shows that fear of rape amplifies females' fear of crime. Do you think it affects your feelings and behaviour when you travel on the underground?"

Q11) "Would you hesitate to report a sexual crime committed against you or ask for help? If so, why?”

\section{Sub-questions}

Included term question

- You said that __ makes you feel fearful in the underground, I'm interested in finding out about all the different kinds of things that make users fearful, are there any other things that make you fearful or affect your use of the tube service?"

- I have learned from some books and research on fear that also makes females fearful, is that right?

- 'are there any other factors affect you feel fear of crime you can think of?' 
- you said that ___ make you feel safe, could you recall any other kinds of things which intervene with your feeling and make you safe when you feel fear in the underground"

\section{References}

Bitner, M.J.: Servicescapes: the impact of physical surroundings on customers and employees. J. Mark. 56(2), 57-71 (1992)

Brantingham, P.L., Brantingham, P.J.: Nodes, paths and edges: considerations of the complexity of crime and the physical environment. J. Environ. Psychol. 13(1), 3-28 (1993)

Brookman, F., Maguire, M., Pierpoint, H., Bennett, T.: Handbook on Crime. Willan Publishing, Cullompton (2010)

Charland, L.C.: The heat of emotion: valence and the demarcation problem. J. Conscious. Stud. 12(8-10), 82-102 (2005)

Colquhoun, I.: Design Out Crime: Creating Safe and Sustainable Communities. Architectural Press, Oxford (2007)

Colombetti, G.: Appraising valence. J. Conscious. Stud. 12(8-10), 103-126 (2005)

Cozens, P., Neale, R., Hillier, D.: Tackling crime and fear of crime while waiting at Britain's railway stations. J. Public Transp. 7(3), 23 (2004)

Clatworthy, S.: Service innovation through touch-points: development of an innovation toolkit for the first stages of new service development. Int. J. Des. 5(2), 15-28 (2011)

Concern, Crime: People's perceptions of personal Security and their concerns about crime on public transport. Department for Transport, England (2004)

Crowe, T.D.: Crime Prevention Through Environmental Design, 3rd edn. Butterworth-Heinemann, Oxford (2013)

Edvardsson, B., Olsson, J.: Key concepts for new service development. Serv. Ind. J. 16(2), 140-164 (1996)

Ellsworth, P.C., Scherer, K.R.: Appraisal processes in emotion. In: Davidson, R.J., Sherer, K.R., Goldsmith, H.H. (eds.) Handbook of Affective Sciences, pp. 572-595. OUP, Oxford (2009)

Ferraro, K.F.: Women's fear of victimization: shadow of sexual assault? Soc. Forces 75(2), 667-690 (1996)

Fielding, N., Thomas, H.: Qualitative interviewing. Researching Social Life, 3rd edn, pp. 123-144. Sage, London (2008)

Franklin, A., Franklin, T.W.: Predicting fear of crime: considering differences across gender. Fem. Criminol. 4(1), 83-106 (2009)

Frijda, N.H.: The Emotion. The Press Syndicate of the University of Cambridge, Cambridge (1986)

Garofalo, J.: The fear of crime: causes and consequences. J. Crim. Law Criminol. 72(2), 839-857 (1981)

Glaser, B.G.: Basics of Grounded Theory Analysis: Emergence Vs. Forcing. Sociology Press, Mill Valley (1992)

Guest, G., Bunce, A., Johnson, L.: How many interviews are enough?: an experiment with data saturation and variability. Field Methods 18(1), 59-82 (2006)

Jackson, J.: A psychological perspective on vulnerability in the fear of crime. Psychol. Crime Law 15(4), 365-390 (2009)

Jackson, J., Stafford, M.: Public health and fear of crime. Br. J. Criminol. 49, 832-847 (2009)

Killias, M.: Vulnerability: towards a better understanding of a key variable in the genesis of fear of crime. Violence Vict. 5(2), 97-108 (1990)

Killias, M., Clerici, C.: Different measures of vulnerability in their relation to different dimensions of fear of crime. Br. J. Criminol. 40, 437-450 (2000)

Kuzel, A.: Sampling in qualitative inquiry. In: Crabtree, B., Miller, W. (eds.) Doing Qualitative Research, pp. 31-44. Sage, Thousand Oaks (1992)

Lang, P.J., Davis, M., Ohman, A.: Fear and anxiety: animal models and human cognitive psychophysiology. J. Affect. Disord. 61, 137-159 (2000)

Lazarus, R.S.: Stress and emotion: a new synthesis. Free Association Books, London (1999)

Loskela, H., Pain, R.: Revisiting fear and place: women's fear of attack and the built environment. Geoforum 31, 269-288 (2000)

Madriz, E.: Nothing bad happens to good girls. University of California Press, Berkeley (1997)

May, D.C., Rader, N.E., Goodrem, S.: A gendered assessment of the "threat of victimization": examining gender differences in fear of crime, perceived risk, avoidance, and defensive behaviors. Crim. Justice Rev. 35(2), 159-182 (2010)

Mayor of London: Mayor's Transport Strategy (2018) 
Moors, A., Ellsworth, P.C., Scherer, K.R., Frijda, N.H.: Appraisal theories of emotions: state of the art and future development. Emot. Rev. 5(2), 119-124 (2013)

Newman: Defensible Space: People and Design in the Violent City. Architectural Press, Oxford (1972)

Oatley, K., Dacher, K., Jenkins, J.M.: Understanding Emotions. Blackwell Publishers Ltd, Oxford (2006)

Pain, R.H.: Social geographies of women's fear of crime. Trans. Inst. Br. Geogr. New Ser. 22, 231-244 (1997)

Pain, R.: Gender, race, age and fear in the city. Urban Stud. 38(5-6), 899-913 (2001)

Plutchik, R.: Emotions and Psychotherapy: a psycho-evolutionary Perspective. In: Plutchik, R., Kellerman, H. (eds.) Emotion: Theory, Research, and Experience Volume 5-Emotion, Psychopathology, and Psychotherapy, pp. 3-42. Academic Press, Inc., Cambridge (1990)

Power, M., Dalgleish, T.: Cognition and Emotion from Order to Disorder, 2nd edn. Psychology Press, Mexico (2008)

Reed, T.B., Wallace, R.R., Rodriguez, D.A.: Transit user perceptions of transit-related crime reduction measures. Transp. Res. Rec. 1731, 130-141 (2000)

Reynald, D.M., Elffers, H.: The future of Newman's defensible space theory: linking defensible space and the routine activities of place. Eur. J. Criminol. 6(1), 25-46 (2009)

Roseman, I.J., Antoniou, A.A., Jose, P.E.: Appraisal determinants of emotions: constructing a more accurate and comprehensive theory. Cogn. Emot. 10(3), 241-277 (1996)

Ross, C.E., Mirowsky, J., Pribesh, S.: Powerlessness and the amplificaiton of threat: neighbourhood disadvantage, disorder, and mistrust. Am. Sociol. Rev. 66, 568-591 (2001)

Russell, P.A.: Fear-evoking stimuli. In: Sluckin, W. (ed.) Fear in Animals and Man, pp. 86-124. Van Nostrand Reinhold, London (1979)

Scherer, K.R.: Appraisal Theory. In: Dalgleish, T., Power, M. (eds.) Handbook of Cognition and Emotion, pp. 637-663. Wiley, Hoboken (1999)

Scott, H.: Stranger danger: explaining women's fear of crime. West. Criminol. Rev. 4(3), 203-214 (2003)

Shostack, G.L.: How to design a service. Eur. J. Mark. 16(1), 49-63 (1993)

Smith, C.A., Kirby, L.D.: Putting appraisal in context: toward a relational model of appraisal and emotion. Cogn. Emot. 23(7), 1352-1372 (2009)

Smith, C.A., Lazarus, R.S.: Appraisal components, core relational themes, and the emotions. Cogn. Emot. 7(3/4), 233-269 (1993)

Strauss, A.L., Corbin, J.M.: Grounded Theory in Practice. Sage Publications, Thousand Oaks (1997)

Thornberg, R., Charmanz, K.: Grounded theory and theoretical coding. In: Flick, U. (ed.) The Sage Handbook of Qualitative Data Analysis, pp. 153-169. SAGE Publications Ltd, Thousand Oaks (2014)

Transport for London: Travel in London: Understanding Our Diverse Communities. Transport for London (2015)

Transport for London: 2017/2018 Crime Statistics Bulletin, 1 April 2017-31 March 2018, Transport for London (2018)

Warr, M.: Fear of victimization: why are women and the elderly more afraid. Soc. Sci. Q. 65, 681-702 (1984)

Whitley, R., Prince, M.: Fear of crime, mobility and mental health in inner-city London, UK. Soc. Sci. Med. 61, 1678-1688 (2005)

Yavuz, N., Welch, E.W.: Addressing fear of crime in public space: gender differences in reaction to safety measures in train transit. Urban Stud. 47(12), 2491-2515 (2010)

Publisher's Note Springer Nature remains neutral with regard to jurisdictional claims in published maps and institutional affiliations.

Hyunjin Kim is an individual researcher, specialized in service design and design management. She did her MA and PhD at Brunel University in the UK. Her research interests include design for sustainable development and service and product design with regard to perceived safety and users' social and physical vulnerability. 